\title{
GARCH and Its Variants' Model: An Application of Crude Oil Distributions in Nigeria
}

\author{
Rasaki Olawale Olanrewaju ${ }^{1, *}$, Ezekiel Oseni \\ ${ }^{1}$ Department of Mathematical Sciences, Pan African University Institute for Basic Sciences, Technology and Innovation (PAUSTI), Nairobi, \\ Kenya \\ ${ }^{2}$ Department of Banking and Finance, University of Lagos, Lagos, Nigeria
}

Email address:

rasakiolawale@gmail.com (R. O. Olanrewaju), zikoseni@yahoo.com (E. Oseni), zikoseni@gmail.com (E. Oseni)

${ }^{*}$ Corresponding author

\section{To cite this article:}

Rasaki Olawale Olanrewaju, Ezekiel Oseni. Garch and Its Variants' Model: An Application of Crude Oil Distributions in Nigeria. International Journal of Accounting, Finance and Risk Management. Vol. 6, No. 1, 2021, pp. 25-35. doi: 10.11648/j.ijafrm.20210601.14

Received: February 27, 2021; Accepted: March 11, 2021; Published: March 26, 2021

\begin{abstract}
This study investigates the need for variants of GARCH model when the former fails to fully embrace clumping volatility of either a positive or negative shock via asymmetrical effect, long-memory, high-frequency, and leverage effect. The volatility effect of distributions of crude oil (prices, barrels produced and exported) in Nigeria, for the period of fifteen (15) (1: 2006 to 8:2020) years obtained from Nigeria National Petroleum Corporation (NNPC) bulletin were examined via GARCH and it variants. Exploratory Data Analysis (EDA) and time plot analyzes were carried-out on the one hundred and seventy-six (176) data points. It was deduced that GARCH $(2,1)$ optimally generalized the prices of crude oil among its variants of gjrGARCH $(2,1)$, apARCH $(2,1), \mathrm{iGARCH}(2,1)$, and csGARCH $(2,1)$, and that positive and negative shocks did not have the same impact on the volatility of prices of crude oil. In a similar vein, iGARCH $(1,1)$ optimized barrels of crude oil produced and exported among eGARCH $(1,1)$, GARCCH $(1,1)$, gjrGARCH $(1,1)$, apARCH $(1,1)$, iGARCH $(1,1)$, and csGARCH $(1,1)$ for the years of studied. However, it was inferred that positive shock as real meaningful impact on the clumping volatility on barrels of crude oil produced and exported while negative shock as no meaningful impact on the volatility on barrels of crude oil produced and exported.
\end{abstract}

Keywords: Crude Oil, Volatility, Positive Shock, Negative Shock, GARCH

\section{Introduction}

The narrative of Nigeria's thriftiness since 1970 will be incomplete without recounting the swinging in crude oil prices, fluctuation of barrels of crude oil produced and exportation as it influences capital expenditure that is entirely financed by crude oil [24]. Revenue earnings from crude oil increased by eight percent to 5.96 trillion in 2006 , also Nigeria experienced four percent drop in oil revenue in 2007 , leaving total earnings to be \#5.72 trillion [12]. The cosmopolitan financial meltdown in 2009 left Nigeria's crude oil revenue to downfall to \#4.84 trillion, representing a thirty-nine percent reduction in income at the end of the year. This unveiled the weakness of the Nigeria economy, but the fault lines were not felt, due to savings when the sales of crude oil were booming. The cosmopolitan economy recovered in 2010 , as well crude oil prices, leading to government income rising to \#7.3 trillion and \#11.1 trillion in 2010 and 2011 respectively. Despite oil prices lagging above $\$ 100$ per barrel in the international market in 2012, oil revenue slowed down substantially. The reduction was due to increase in crude oil redefined by the US, which in turn led to reduction in imports from Nigeria and Nigeria's inability to meet-up production targets.

In 2014, Nigeria crude oil revenue experienced foster hit due to falling global oil prices and US not importing from Nigeria. It was believed that the unsustainability led to continuous depending on oil revenue, considering its variation. The viewpoint did not show that things will be amended in the following year (2015) and that oil prices might not rise beyond eighty US dollar within the fiscal period. Nigeria set an achievable oil benchmark price so as to reach a right-winger price of $\$ 55$ per barrel. This raised Nigeria's projected budget deficit from \#1 trillion to \#2 trillion and helped oil production 
to skyrocket to $2.23 \mathrm{~m}$ barrels per day [25]. Invariably, crude oil production, price and exportation importance to the continuity and improvement of Nigeria economy cannot be over-emphasized. Majority of Nigeria crude oil is usually sold unrefined, and when refined the end-products includes diesel, petrol, and heavy liquids $[1,11]$.

The study of volatility has been defined as the flippancy attached to returns (e.g. crude oil prices, its production and exporting etc.); that is, it is nothing but the measurement of risk (the stochastic variation or variance is been characterized and extracted from the subjected analysis). These changing levities are empirical distributions that are used to study financial returns of crude oil price, its production as well exporting [18]. This flippancy is normally in terms of clumping volatility and leptokurtosis that are usually present in crude oil prices, its volume/barrels produced and exportation [20]. Observations with these changing levities (trend) of this type in the analysis of crude oil distributional time series have led to the adaptation and uses of wide range of time-varying variance models to estimate and predict volatility. This led to the development of econometrics invention of adaptive methods for modeling the mean value of interested time-varying variable (s); Autoregressive Integrated Moving Average (ARIMA) by Box \& Jenkins [4]. ARIMA deficiency was based on center of location variation (conditional mean-value) alone, whereas designing of methods for the modeling of phenomenon's volatility is sole on changing of variance value (conditional variance-value) or both [5]. This firstly led to the propounding and proposing of Autoregressive Conditional Heteroskedaticity (ARCH) by Engle [10]; the model was applied to capture stock market volatility, before an extension, better modification and specification was made by Bollerslev [3] and Taylor [27] that led to Generalized Autoregressive Conditional Heteroskedaticity (GARCH). They solved the problem of parsimony from infinity to two requirements as it was based on an infinite ARCH specification. The GARCH model has been applied successfully in various discipline (time series, microeconomic and macroeconomic analysis, financial returns etc.) for modeling the changing variation (volatility) [9, 13, 26].

The ARCH and GARCH models were designed to capture clumping volatility and leptokurtosis, but their demerit was that their distributions were symmetric. The principal disadvantage of the GARCH model has been it unsuitability to model asymmetrical effect in cases where volatility can take either a positive or negative shock. In the case of martingale models, a decrease or increase in returns can be interpreted as negative or positive effect. If the fall in returns is accompanied by an increase in fluctuation greater than the fluctuation caused by an increase in returns, such a model is said to have failed in modeling "leverage effect" [22].

According to Maqsood et al. [21], crude oil analysis possessed the trait of thick-tails, which are thicker than that of the Gaussian distribution. In other words, GARCH model do not fully embrace this property of thick/heavy tails, which are so much evident in the behavior of crude oil time series analysis. To address this problem, variants and modified extensions of GARCH such as Exponential Generalized Autoregressive Conditional Heteroskedaticity (eGARCH) model by Nelson [23], Glosten, Jagannathan and Runkle-Generalized Autoregressive Conditional Heteroskedaticity (GJR-GARCH) by Glosten et al. [14], the Asymmetric Power ARCH (APARCH) by Ding et al. [8], Threshold Generalized Autoregressive Conditional Heteroskedaticity (TGARCH) and Fractional Generalized Autoregressive Conditional Heteroscedaticity (FGARCH) are proposed and will be considered. The stylized facts about conditional volatility such as persistence of volatility, mean reverting behavior and asymmetric impacts of negative and positive return of each of the aforementioned GARCH innovations will be investigated.

\section{Literature Review}

Models have their strengths and weaknesses; it is important to correctly distinguish between various models in order to find the one which provides the most accurate predictions.

Few articles on behavioral of stock returns volatility in both theoretical and applications had been developed and applied to emerging stock markets and crude oil distributions. In addition, few studies have been carried-out in the varying of ARCH and GARCH models innovation in order to juxtapose robustness and performance of each innovation. In collaboration, [28] claimed that the magnitude of leptokurtosis introduced by the GARCH process does not always capture the leptokurtosis that is present in the high-frequency financial asset. Thus, there is a fair amount of evidence that the conditional distribution of the error term does violate normality assumption.

The serial correlation in stock returns led to the proliferation of ARCH-type models, which seek to incorporate the information contained in the tails of the distribution of stock returns into time series models. Another setback encountered by Beine et al. [2] when using GARCH models was that they do not always fully embrace the thick tails property of high frequency financial time series. Both $\mathrm{ARCH}$ and GARCH models capture volatility clustering and leptokurtosis, but their distribution is symmetric, they fail to model the "leverage effect" adequately.

The use of asymmetric stable density was re-modified into ARCH model with the use of skewed Student- $t$ distribution to capture both skewness and kurtosis by Liu \& Brorsen [19], which was later extended to the GARCH framework by Lambert \& Laurent [16] and Lambert \& Laurent [17]. To improve the fit of GARCH and eGARCH models into international markets, the relative performance of the asymmetric Normal Mixture Generalized Autoregressive Conditional Heteroskedasticity (NM-GARCH) and the benchmarked GARCH models were investigated with the daily stock market returns of the Johannesburg Stock Exchange, South-Africa by Cifter [6]. The predictive performance of the NM-GARCH model was compared against a set of the GARCH models with the normal, the 
student- $t$, and the skewed-student- $t$ distributions. The empirical results showed that the NM-GARCH outperformed all other competing models according to Christoffersen [7]'s tail-loss and White [29]'s reality check tests. This evidence maintained that mixture of errors improves the predictive performance of volatility models.

The GARCH-type models were used to estimate the volatility of the daily returns of the Kenyan stock market by Maqsood et al. [21]. Their results revealed that the volatility process was highly persistent, thus, giving evidence of the existence of risk premium for the NSE index return series. This in turn supports the positive correlation hypothesis: that is between volatility and expected stock returns. Another fact revealed by the results is that the asymmetric GARCH models provide better fit for NSE than the symmetric models. This proves the presence of "leverage effect" in the NSE return series.

Research was focused on fluctuations in gas prices across different regions of the US and the effects of exogenous shocks on their volatility by using uniformly timed data by Hassan \& Regassa [15]. They used a Generalized Autoregressive Conditional Heteroscedasticity (GARCH) model and its variant (GARCH-GED) to measure the persistence of shocks to volatility and the asymmetric effects of these shocks. The results showed evidence of high persistence of shocks to volatility and signs of an asymmetric behavior in volatility across regions, which imply that gas prices may react differently to good news relative to bad news. The study sheds some light on understanding of the behavior of gas prices in the US better, with major implications for investors in the commodity markets.

This research work will build on and extend on both [15], and [21]'s description and work by extending the GARCH model variants to eGARCH, APARCH, GJR-GARCH, FIGARCH, TGARCH innovations via specifications, parameter estimations, performance comparison, optimal capturing of the "leverage effect", and comparison of their error indexes. It has been suggested in literature to work out the variants of GARCH model for comparison of model capture, model performance and forecasting indexes seek when normality assumption is violated and modification of GARCH model is needed. The need for better understanding of volatility effects of distributions of crude oil on the Nigerian financial market is critical to the survival of the country's economy. Crude oil being its major export, and source of income. This link is critical as swings in crude oil price have direct implication for exchange rate. Hence, the study focuses on modeling of variants of GARCH models with re-modification technique, so as to estimate the volatility associated to crude oil prices, production and exportation.

\section{Theoretical Analysis}

1. An Autoregressive Conditional Heteroskedaticity $(\mathrm{ARCH})$ of order "p", that is, $\operatorname{ARCH}(q)$ model with " $\mu$ " as the conditional mean for the return for period " $t$ " and time varying conditional variance can be expressed as:

$$
\begin{gathered}
\varepsilon_{t}=z_{t} \sigma_{t} ; z_{t} \sim \text { i.i.d } N(0,1) \\
\sigma_{t}^{2}=\omega+\sum_{i=1}^{p} \alpha_{i} \varepsilon_{t-i}^{2}
\end{gathered}
$$

Where $N($.$) is a Probability Density Function (PDF) of the$ standardized normal distribution with mean zero and unit variance. The conditional variance $\varepsilon_{t}$ in (1) is indeed an increasing function of the square of the shock that happened in $t-1$. As the ARCH model can explain the volatility-clustering, if the magnitude of $\varepsilon_{t-1}$ is going to be large, then $\sigma^{2}$ and accordingly $\varepsilon_{t}$ are likely to be large. $\omega$ is the intercept.

2. A Generalized Autoregressive Conditional Heteroscedaticity (GARCH) of order "p" and "q", that is, $\operatorname{GARCH}(p, q)$. The time varying conditional variance can be expressed as:

$$
\begin{gathered}
y_{t}=\sigma_{t} \varepsilon_{t} \\
\sigma_{t}^{2}=\omega+\sum_{i=1}^{q} \alpha_{i} \varepsilon_{t-i}^{2}+\sum_{j=1}^{p} \beta_{j} \sigma_{t-j}^{2}
\end{gathered}
$$

Where $\omega>0, \alpha_{i}, \beta_{j} \geq 0$, such that the innovation sequence $\varepsilon_{i}=(-\infty,+\infty)$ is independently and identically distributed with mean zero and unity variance. The persistence of the model $\widehat{R}$ is

$$
\widehat{R}=\sum_{i=1}^{q} \alpha_{i}+\sum_{j=1}^{p} \beta_{j}<1
$$

Using backshift operator $-L-,(2)$ could re-written as

$$
\sigma_{t}^{2}=\omega+\alpha(L) \varepsilon_{t}^{2}+\beta(L) \sigma_{t}^{2}
$$

Where $L$ is the $\alpha(L)=\alpha_{1} L+\alpha_{2} L^{2}+\cdots \cdots+\alpha_{q} L^{q}$ and $\beta(L)=\beta_{1} L+\beta_{2} L^{2}+\cdots \cdots+\beta_{p} L^{p}$

$\sigma_{t}^{2}$ is the conditional variance, $\omega$ is the intercept, and $\varepsilon_{t}$ is the residual from the mean.

$\operatorname{ARCH}(\mathrm{q})$ parameters are $\alpha_{1}, \alpha_{2}, \cdots$,

$\operatorname{GARCH}(\mathrm{p})$ parameters are $\beta_{1}, \beta_{2}, \cdots$,

Variance intercept parameter is ' $\omega$ '

GARCH model capture is volatility clustering which may be quantified in the persistence parameter GARCH model this may be calculated as;

$$
\widehat{R}=\sum_{i=1}^{q} \alpha_{i}+\sum_{j=1}^{p} \beta_{j}
$$

3. A GJR-GARCH model for positive and negative shocks via asymmetrical conditional variance with the use of 
indicator function $I$ was introduced by Glosten et al.[14], and can be expressed as:

$$
\sigma_{t}^{2}=\omega+\sum_{i=1}^{q}\left(\alpha_{i} \varepsilon_{t-i}^{2}+\gamma_{i} I_{t-i} \varepsilon_{t-i}^{2}\right)+\sum_{j=1}^{p}\left(\beta_{j} \sigma_{t-j}^{2}\right)
$$

$\operatorname{ARCH}(\mathrm{q})$ parameters are $\alpha_{1}, \alpha_{2}, \cdots$,

Leverage (q) parameters are $\gamma_{1}, \gamma_{2}, \ldots$,

GARCH (p) parameters are $\beta_{1}, \beta_{2}{ }^{\prime}, \ldots$,

Variance intercept parameter is ' $\omega$ '

The indicator function $I$ takes on value of one for $\varepsilon \leq 0$ and zero otherwise.

The persistence of the model $\widehat{R}$ is

$$
\widehat{R}=\sum_{i=1}^{q} \alpha_{i}+\sum_{j=1}^{p} \beta_{j}+\sum_{i=1}^{q} \gamma_{i k}
$$

Where ' $k$ ' is the expected value of the standardized residuals $z_{t}$ below zero (effectively the probability of being below zero)

$$
k=E\left[I_{t-i} z_{t-i}^{2}\right]=\int_{-\infty}^{0} f(z, 0,1, \cdots \cdots) d z
$$

4. A Fractionally Integrated Generalized Autoregressive Conditional Heteroscedasticity (FIGARCH or FGARCH) model, for capturing long memory (essence hyperbolic memory), can be expressed as:

$$
\begin{aligned}
\sigma_{t}^{2} & =\omega-\sum_{i=1}^{p} \beta_{i} \varepsilon_{t-i}^{2}+\sum_{j=1}^{q} \alpha_{j} \varepsilon_{t-j}^{2}-\bar{\varepsilon}_{t-j}^{2}+\sum_{j=1}^{q} \alpha_{j} \bar{\varepsilon}_{t-j}^{2}+\sum_{i=1}^{p} \beta_{i} \sigma_{t-i}^{2} \\
& =\left(\omega-\bar{\varepsilon}_{t-j}^{2}\right)+\sum_{j=1}^{q} \alpha_{j}\left(\varepsilon_{t-j}^{2}+\bar{\varepsilon}_{t-j}^{2}\right)+\sum_{i=1}^{p} \beta_{i}\left(\sigma_{t-j}^{2}-\varepsilon_{t-j}^{2}\right)(9)
\end{aligned}
$$

5. The Asymmetric Power Autoregressive Conditional Heteroscedasticity (APARCH) model by Ding et al. [8] allows for both leverage and the Taylor effect, named after [27] who observed that the sample autocorrelation of absolute returns was usually larger than that of squared returns. It can be expressed as:

$$
\sigma_{t}^{\delta}=\omega+\sum_{i=1}^{q} \alpha_{i}\left(\left|\varepsilon_{t-i}\right|-\gamma_{i} \varepsilon_{t-i}\right)^{\delta}+\sum_{j=1}^{p}\left(\beta_{j} \sigma_{t-j}^{\delta}\right)
$$

Where $\delta$ (a positive real number) is the Box-Cox transformation of $\sigma_{t}, \gamma_{i}$ is the coefficient in the leverage effect. The persistence of the model $\widehat{R}$ is given by

$$
\widehat{R}=\sum_{i=1}^{q} \alpha_{i} k_{j}+\sum_{j=1}^{p} \beta_{j}
$$

Where ' $k_{j}$ ' is the expected value of the standardized residuals $z_{t}$ under the Box-Cox transformation of the term, which includes the leverage coefficient $\gamma_{i}$

$$
k_{j}=E\left[|z|-\gamma_{i} z\right]=\int_{-\infty}^{\infty}\left(|z|-\gamma_{i} z\right)^{\delta} f(z, 0,1, \cdots \cdots) d z
$$

Where

$\mathrm{ARCH}$ (q) parameters are $\alpha_{1}, \alpha_{2}, \ldots$,

Leverage (q) parameters are $\gamma_{1}, \gamma_{2}, \ldots$,

Power parameter is ' $\delta$ '

GARCH (p) parameters are $\beta_{1}, \beta_{2}{ }^{\prime}, \ldots$,

Variance intercept parameter is ' $\omega$ '

It is to be note that

1) The Asymmetric Power ARCH (APARCH) equals the GARCH model when $\delta=2$ and $\gamma_{i}=0$.

2) The Asymmetric Power ARCH (APARCH) equals GJR-GARCH (GJRGARCH) model when $\delta=2$.

3) The Asymmetric Power ARCH (APARCH) equals Threshold GARCH (TGARCH) model o when $\delta=1$.

4) The Asymmetric Power ARCH (APARCH) equals the Non-linear ARCH model when $\delta=0$.

6. The Exponential Generalized Autoregressive Conditional Heteroscedasticity (eGARCH) as defined can be expressed as:

$$
\log \left(\sigma_{t}^{2}\right)=\omega+\sum_{j=1}^{q}\left(\alpha_{j} z_{t-j}+\gamma_{j}\left(\left|z_{t-j}\right|-E\left|z_{t-j}\right|\right)\right)+\sum_{i=1}^{p} \beta_{i} \log \left(\sigma_{t-i}^{2}\right)
$$

Where the coefficient $\alpha_{j}$ captures the sigs effect and $\gamma_{j}$ captures the size effect. The expected value of the absolute standardized innovation, $z_{t}$ is

$$
E\left|z_{t}\right|=\int_{-\infty}^{\infty}|z| f(z, 0,1, \cdots \cdots) d z
$$

The persistence of the model $\widehat{R}$ is given by

$$
\widehat{R}=\sum_{j=1}^{p} \beta_{j}
$$

\section{Analysis and Discussion}

The datasets used in this research were secondary average monthly of crude oil prices sold, production in barrels and exportation in barrels all derived from market portfolio/sector of crude oil section of obtained from Nigeria National Petroleum Corporation (NNPC) bulletin. The raw datasets covered the period of fifteen (15) years from 1: 2006 to 8:2020, with the start and end points being based purely on the data availability at the time of this study. The significant of this research is the need for better understanding of the effects of crude oil on Nigeria financial market and survival of the economy, since the country's income revenue depend solely of 
the sales of crude oil. Crude oil production, exportation and price fluctuations affects the Nigeria economy through a number of channels. It is undebatable that the effect of crude oil (production, prices and barrels exported) usually constitute to the periodic vacillating of financial markets, stock market performances, general price level and adjustments in exchange rate policy.

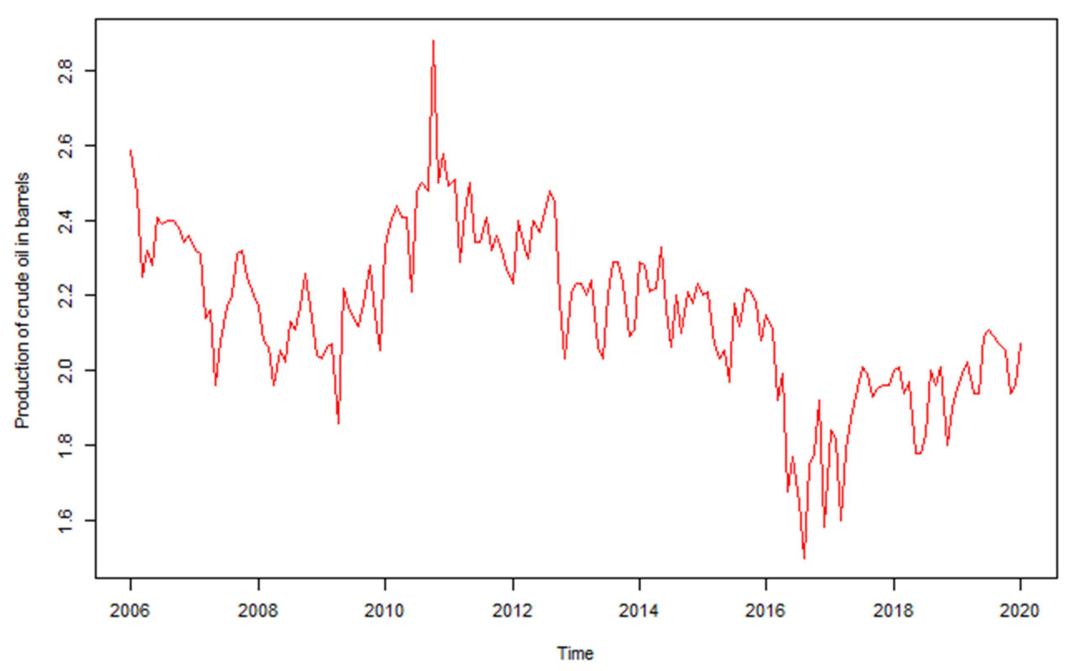

(a)

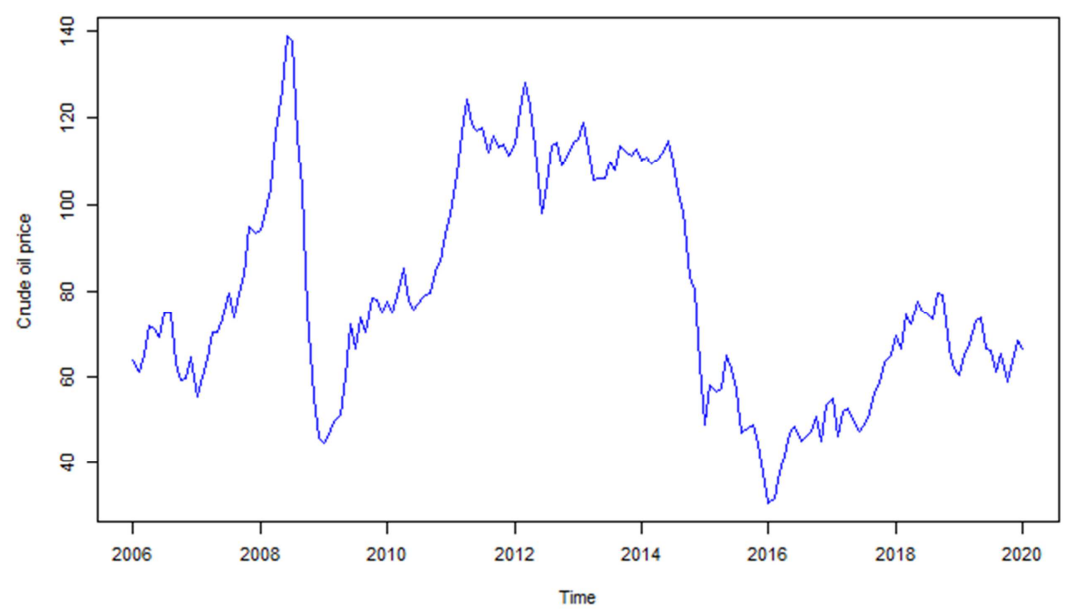

(b)

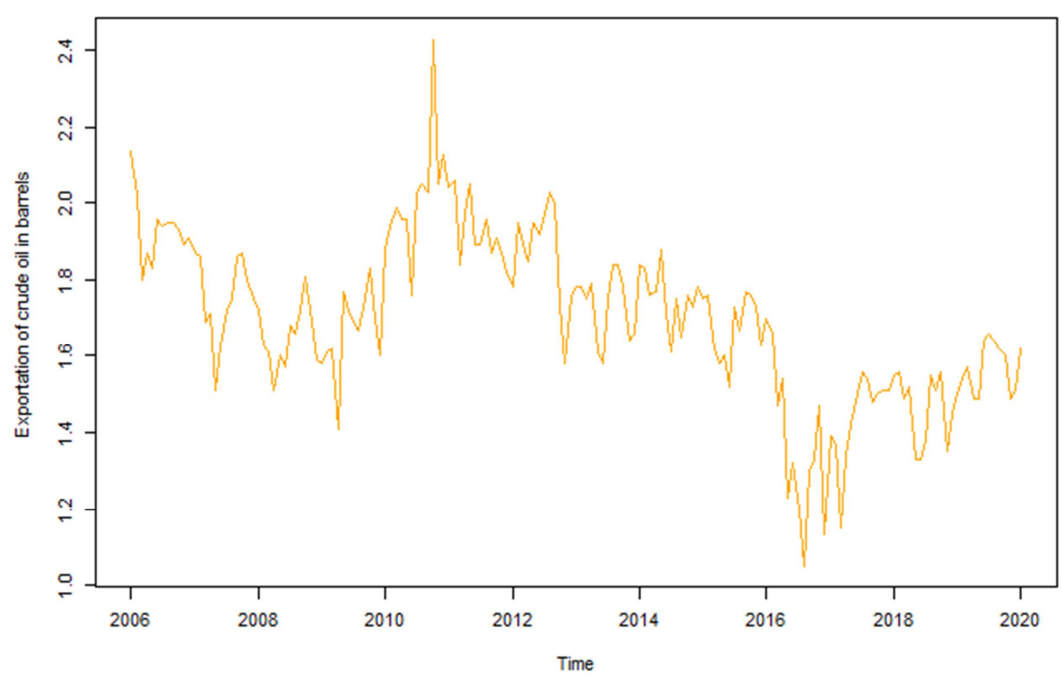

(c)

Figure 1. The Time Plots for Prices Crude Oil and Barrels Produced, and Exported. 
From figure 1 and the first time plot (a) for production of crude oil in barrels from 1: 2006 to 8:2020 above, the barrels of crude oil production maintained a falling dwindling of production from 2.6 to 1.9 million barrels monthly from 2006 to fourth quarter of 2009. A constant increment in the production was experienced from late 2009 to late 2011, such that the highest production of 2.9 million barrels was in the last two months of 2011. A zig-zag production between 2.0 and 2.4 million of barrels manifested from 2012 to mid-2016 and minima production of 1.5 million barrels was at the beginning of 2017. However, since 2017 till date the production has not surpassed 2.2 million barrels monthly. From the second time plot (a) for average prices of crude oil monthly, the average monthly prices of crude oil dangled between $\$ 65$ and $\$ 75$ throughout 2006 to mid-2007. The price maintained a constant skyrocketing from second quarter of 2008 till fourth quarter of 2008 with the highest favourable price of $\$ 140$ experienced, the price drastically maintained a falling activities throughout 2009. An uprising price from $\$ 45$ to $\$ 120$ was recorded from 2010 till 2014 . A sporadic constant devaluation in the price was recorded form the 2015 to beginning of 2016, such that a ridiculous and disturbing price of \$20 was recorded in January, 2016 in the history of crude oil sold in Nigeria. However, since January 2016, a crawling increment of the crude oil price (between \$30 and \$80) has been the international crude oil price sold to the rest of the world by Nigeria.

From the third time plot (c) for the barrels of crude oil exported from 1: 2006 to 8:2020 above, the barrels of crude oil exported preserved a diminishing barrels of exportation from 2.6 to 1.9 million barrels monthly from 2006 to fourth quarter of 2009 in a similar vein to production in barrels. An invariant increment in the barrels exported was recorded from late 2009 to late 2011, such that 2.9 million barrels were exported in the last two months of 2011. A zig-zag production between 2.0 and 2.4 million of barrels manifested from 2012 to mid-2016 and minima production of 1.5 million barrels was at the beginning of 2017 . However, since 2017 till date the production has not surpassed 2.2 million barrels monthly.
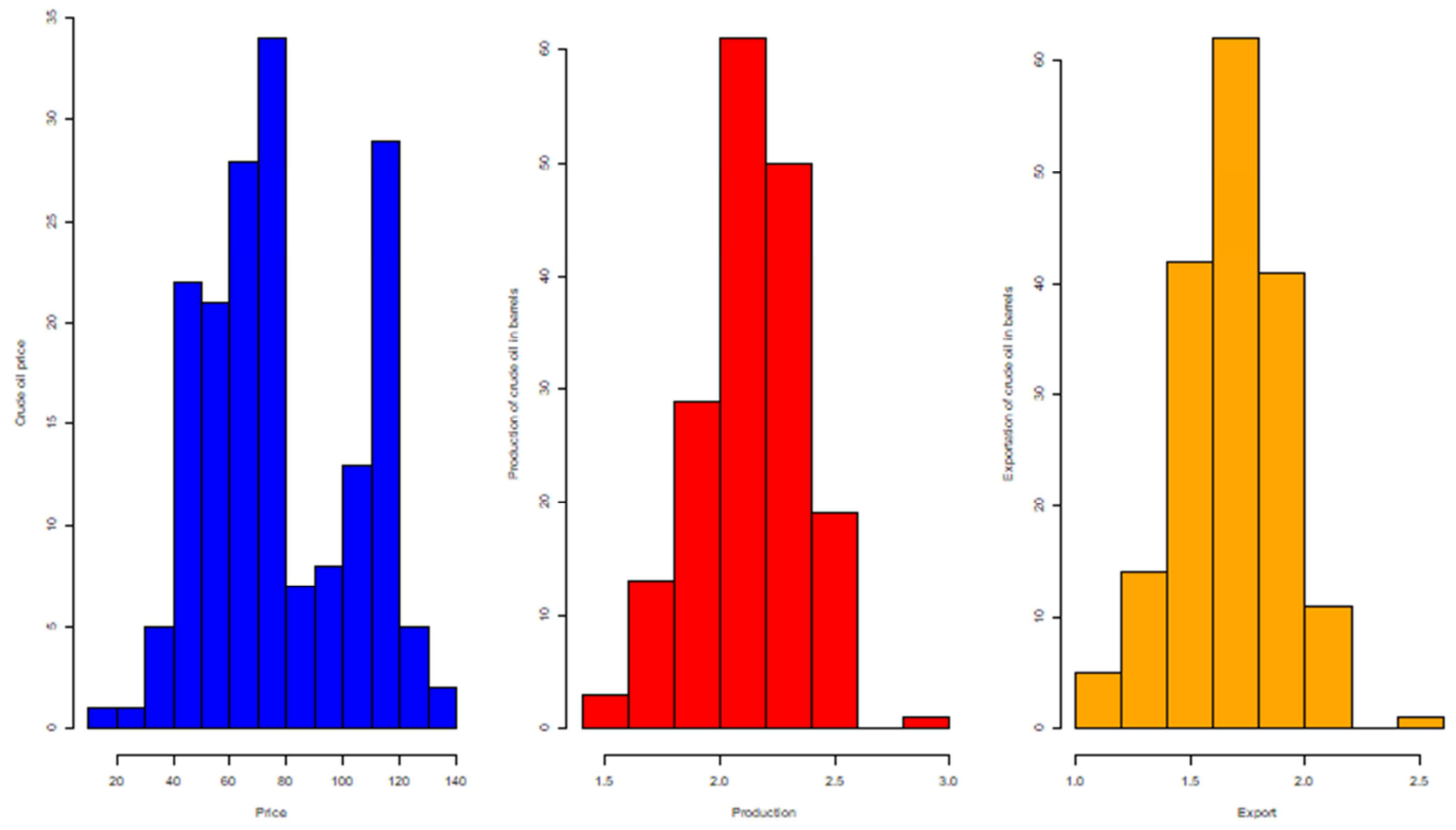

Figure 2. Histograms of Crude Oil Prices, Barrels Produced and Exported.

From figure 2 above, the first histogram in colour blue stands for the prices of crude oil, accruable and approximately, 35 million barrels of crude oil were averagely sold at $\$ 80$ in some of the months within the sixteen years' (1: 2006 to 8:2020) interval, 30 and 28 million barrels were averagely sold at $\$ 120$ and $\$ 75$ in some of the months within the studied years' interval. Approximately, 23, 20, 13, 6, 8, 5, 5 and 3 million barrels were averagely sold at $\$ 50, \$ 60, \$ 110$, $\$ 90, \$ 110, \$ 40, \$ 120$ and $\$ 140$ respectively in some of the months. In a similar vein, from the second and third histograms for production of crude oil and exported in barrels, averagely, 60 million barrels was the highest produced as well as exported in one of the one hundred and ninety-two (192) months studied.

\subsection{Exploratory Data Analysis (EDA) of the Crude Oil Distributions}

The exploratory data analysis of the distributions of the crude oil was summarized and presented in Table 1 below. 
Table 1. Exploratory Data Analysis (EDA) Analysis.

\begin{tabular}{llll}
\hline Statistic & Price & Production & Exportation \\
\hline Mean & 79.59 & 2.15 & 1.70 \\
Median & 74.72 & 2.17 & 1.72 \\
Maximum & 138.74 & 2.88 & 2.43 \\
Minimum & 30.66 & 1.50 & 1.05 \\
Variance & 0.0503 & 0.0503 & 0.0503 \\
Skewness & 0.3186 & -0.1591 & -0.1591 \\
Kurtosis & 1.9576 & 3.3950 & 3.3950 \\
Jarque-Bera Test Statistic & 8.0918 & 1.3282 & 1.3282 \\
P-value for Jarque-Bera Test & 0.01749 & 0.5147 & 0.5147 \\
Sum & 13708.8 & 376.32 & 297.12 \\
Anscombe-Glynn Test Statistic & -5.7829 & 1.201 & 1.201 \\
P-value Anscombe-Glynn Test & $7.342 \mathrm{e}-09$ & 0.2298 & 0.2298 \\
\hline
\end{tabular}

Units: Price in Dollars; Production- Barrels in millions; Exportation- Barrels in millions

It is obvious from table 1 that prices of crude oil, barrels produced and exported for the fifteen years of study maintained the same miniature variation of 0.0503 (of $5.03 \%$ ) among the clustered observations. The distribution of prices of crude oil, volume produced and exported in barrels have estimated coefficients of skewness to be $0.3186,-0.1591$, -0.1591 respectively, which means the distribution of volume produced and exported in barrels were negatively skewed lesser than zero while the prices of crude oil for the fifteen years was positively skewed. In a similar vein, the kurtosis coefficient of the distribution of volume of crude oil in barrels produced and exported was estimated to be $(3.3950>3$; leptokurtic) with $\mathrm{P}$-value $=0.2298>0.05$ while the kurtosis coefficient of price of crude oil was estimated to be $(1.9576<3$; platykurtic) with $\mathrm{P}$-value $=7.342 \mathrm{e}-09<0.005$ for the period of study. The Jarque-Bera statistic coefficients for the distribution of volume of crude oil in barrels produced and exported coincide and was estimated to be 1.3282, which denotes that its errors are not normally distributed with the insignificant values $\mathrm{P}$-value $=0.5147>0.05$, which may be due to fluctuation or jump, while the Jarque-Bera statistic coefficients for the distribution of price of crude oil for the period of study was estimated to be 8.0918 , which means that, its errors is not normally distributed with the significant value P-value $<0.01749<0.05$.

Table 2. Stationarity Tests for the Distributions of Crude Oil.

\begin{tabular}{|c|c|c|c|c|c|c|c|c|}
\hline \multirow{2}{*}{ Crude oil } & \multicolumn{2}{|c|}{ Augmented Dickey-Fuller Test } & \multicolumn{2}{|c|}{ Phillips-Perron Unit Root Test } & \multicolumn{2}{|c|}{ KPSS Test for Level Stationarity } & \multicolumn{2}{|c|}{ Box-Pierce Test } \\
\hline & Statistic & P-value & Statistic & P-value & Statistic & P-value & $\chi^{2}$ & P-value \\
\hline Price & -2.512 & 0.363 & -11.054 & 0.482 & 0.684 & 0.015 & 157.73 & $<2.2 \mathrm{e}-16$ \\
\hline Production & -2.345 & 0.433 & -34.882 & 0.010 & 1.644 & 0.010 & 118.47 & $<2.2 \mathrm{e}-16$ \\
\hline Exportation & -2.345 & 0.433 & -34.882 & 0.010 & 1.644 & 0.010 & 118.47 & $<2.2 \mathrm{e}-16$ \\
\hline
\end{tabular}

From table 2 above, the Augmented Dickey-fuller (ADF) statistic with negative coefficient connote the likelihood of rejection of the null hypothesis that there is a unit root. Hence, since the ADF statistic for the distribution of crude oil prices, production and exportation in barrels are -2.5116, -2.3445, -2.3445 with $\mathrm{P}$-values $=0.3627,0.4325,0.4325>0.05$ respectively, the hypothesis that there is a unit root at $5 \%$ level of confidence is rejected. The Phillips-Perron unit root test is used to test the null hypothesis that a series is integrated of order 1 . However, since the P-values of Phillips-Perron unit root test for barrels of crude oil produced and exported are $0.01<0.05$ each, it implies that integrated order of 1 could be occurred by chance, while the P-value for the Phillips-Perron unit root test for prices of crude oil is $0.4818>0.05$, which means that integrated order cannot be 1 . The Box-Pierce test is used to ascertain whether the residuals are white noise and it statistic follows a $\chi^{2}$ distribution. Since the $\mathrm{P}$-values for the three distributions of the crude oil coincide to be $<2.2 \mathrm{e}-16<0.05$, it implies the residuals of the three distributions follow a white noise.

\subsection{Model Selection for Autoregressive Model for the Distributions of Crude Oil}

Table 3. Model Selection for Autoregressive Model for Crude Oil Price.

\begin{tabular}{llllll}
\hline Order & Log-likelihood & AIC & BIC & RMSE & R $^{\mathbf{2}}$ \\
\hline AR (1) & -316.098 & 634.2 & 637.3 & 6.4341 & $93.73 \%$ \\
AR (2) & -304.762 & 613.5 & 619.8 & 6.0114 & $94.527 \%$ \\
AR (3) & -303.501 & 613 & 622.4 & 5.9651 & $94.611 \%$ \\
AR (4) & -303.489 & 615 & 627.5 & 5.9647 & $94.612 \%$ \\
\hline
\end{tabular}

\begin{tabular}{llllll}
\hline Order & Log-likelihood & AIC & BIC & RMSE & $\mathbf{R}^{2}$ \\
\hline AR (5) & -303.237 & 616.5 & 632.1 & 5.9552 & $94.629 \%$ \\
AR (6) & -303.236 & 618.5 & 637.3 & 5.9551 & $94.629 \%$ \\
\hline
\end{tabular}

Table 4. Model Selection for Autoregressive Model for Barrels of Crude Oil Produced.

\begin{tabular}{llllll}
\hline Order & Log-likelihood & AIC & BIC & RMSE & R $^{2}$ \\
\hline AR (1) & 364.696 & -727.4 & -724.3 & 0.1141 & $72.541 \%$ \\
AR (2) & 370.077 & -736.2 & -729.9 & 0.1106 & $74.23 \%$ \\
AR (3) & 370.739 & -735.5 & -726.1 & 0.1102 & $74.394 \%$ \\
AR (4) & 370.816 & -733.6 & -721.1 & 0.1102 & $74.414 \%$ \\
AR (5) & 371.431 & -732.9 & -717.2 & 0.1098 & $74.601 \%$ \\
AR (6) & 372.155 & -732.3 & -713.5 & 0.1092 & $74.85 \%$ \\
\hline
\end{tabular}

From table 3 to table 5, the autoregressive generalization for the distributions of crude oil (prices, barrels produced and exported) coincided to give optimal generalization at order two, that is AR (2). The autoregressive models the distributions of crude oil (prices, barrels produced and exported) is as follow:

$$
\begin{gathered}
\hat{y}_{\text {Price }}=0.3072 y_{t-1}-0.3531 y_{t-2} \sim(79.5927,10.081) \\
\hat{y}_{\text {Production }}=0.6415 y_{t-1}+0.2509 y_{t-2} \sim(2.1502,0.0791) \\
\hat{y}_{\text {exportation }}=0.6415 y_{t-1}+0.2509 y_{t-2} \sim(1.7002,0.0791)
\end{gathered}
$$

Based on the three fitted models, the distribution of barrels of crude oil produced and exported did not only coincide in 
terms of autoregressive coefficients possessed to be $\mathrm{AIC}=-727.4 ; \quad \mathrm{BIC}=-729.9 ; \quad \log$-likelihood $=370.077$; $\mathrm{RMSE}=0.1106$, but also gives a robust model performance that best explained the effect of the trend component and minimum model error compare to the distribution of crude oil prices with higher coefficient of variation and indexes $\mathrm{AIC}=-727.4 ; \quad \mathrm{BIC}=619.8 ; \quad$ Log-likelihood=-316.098; $\mathrm{RMSE}=6.0114$. It is to be noted that after AR (6), that is after autoregressive of order six for the distributions, the model error accompanied increased incrementally.

\subsection{Model Selection for GARCH Variants'Models for the Prices of Crude Oil}

Table 5. Model Selection for Autoregressive Model for Crude Oil Exported.

\begin{tabular}{lllll}
\hline Order & Log-likelihood & AIC & BIC & RMSE \\
\hline AR (1) & 364.696 & -727.4 & -724.3 & 0.1141 \\
AR (2) & 370.077 & -736.2 & -729.9 & 0.1106 \\
AR (3) & 370.739 & -735.5 & -726.1 & $72.541 \%$ \\
AR (4) & 370.816 & -733.6 & -721.1 & 0.1102 \\
AR (5) & 371.431 & -732.9 & -717.2 & 0.1102 \\
AR (6) & 372.155 & -732.3 & -713.5 & 0.1098 \\
\hline
\end{tabular}

RMSE=Residual Mean Square Error; $\mathrm{R}^{\wedge} 2=$ Adjusted-R-Square

Table 6. Model Selection for GARCH Model for Crude Oil Prices.

\begin{tabular}{lllll}
\hline GARCH Order & Log-likelihood & Akaike & Bayes & Shibata \\
\hline c $(1,1)$ & -537.5875 & 6.4330 & 6.5441 & 6.4306 \\
c $(2,1)$ & -531.7414 & 6.3756 & 6.5053 & 6.3724 \\
c $(2,2)$ & -531.7414 & 6.3875 & 6.5356 & 6.3833 \\
c $(3,1)$ & -531.8715 & 6.3946 & 6.5405 & 6.3856 \\
c $(3,2)$ & -531.8715 & 6.4008 & 6.5675 & 6.3955 \\
c $(3,3)$ & -531.8715 & 6.4127 & 6.5979 & 6.4282 \\
\hline
\end{tabular}

Table 7. Summary of GARCH variants Models for crude Oil Prices.

\begin{tabular}{|c|c|c|c|c|c|}
\hline GARCH variants & Log-likelihood & Akaike & Bayes & Shibata & Hannan-Quinn \\
\hline gjrGARCH $(2,1)$ & -537.4986 & 6.4674 & 6.6341 & 6.4621 & 6.5351 \\
\hline apARCH $(2,1)$ & -530.6733 & 6.3985 & 6.5837 & 6.3920 & 6.4737 \\
\hline iGARCH $(2,1)$ & -534.1413 & 6.3922 & 6.5033 & 6.3898 & 6.4373 \\
\hline $\operatorname{csGARCH}(2,1)$ & -532.3638 & 6.4067 & 6.5734 & 6.4014 & 6.4743 \\
\hline
\end{tabular}

Table 8. Optimal GARCH c (2,1) Coefficients for Crude Oil Price.

\begin{tabular}{|c|c|c|c|c|}
\hline Coefficients & Estimate & Std. Error & t-value & $\operatorname{Pr}(>|t|)$ \\
\hline $\mathrm{mu}$ & 65.6450 & 5.566595 & 11.7927 & 0.000000 \\
\hline ar1 & 0.9835 & 0.0171 & 57.5644 & 0.000000 \\
\hline ar2 & 0.6872 & 0.5904 & 23.9079 & 0.000000 \\
\hline mal & 0.2089 & 0.0763 & 2.7403 & 0.006139 \\
\hline omega & 17.2185 & 5.8229 & 2.9570 & 0.003106 \\
\hline alpha1 & 0.11408 & 0.0893 & 1.2778 & 0.201310 \\
\hline alpha2 & 0.43181 & 0.1559 & 2.7698 & 0.005609 \\
\hline beta1 & 0.00000 & 0.1987 & 0.0000 & 0.000000 \\
\hline
\end{tabular}

Sign Bias Test

\begin{tabular}{lll}
\hline Coefficients & t-value & prob sig \\
\hline Sign Bias & 1.0337 & 0.3028 \\
Negative Sign Bias & 0.3497 & 0.7270 \\
Positive Sign Bias & 0.2167 & 0.8287 \\
Joint Effect & 2.5656 & 0.4636 \\
\hline
\end{tabular}

$$
\sigma_{t}^{2}=17.2185+0.9835 y_{t-1}+0.6872 y_{t-2}+0.2089 \varepsilon_{t-1}+0.11408 \alpha_{1}+0.11408 \alpha_{2}+0.0000 \beta_{1}
$$

From table 6 to table 8, the first table unveiled the model selection for GARCH model for prices of crude oil, it can be deduced that the optimal integrated order after first differencing of the series for crude oil prices was c $(2,1)$ ( that is optimal at AR (2) and MA (1) with minima log-likelihood $=-531.7414$, Akaike=6.3756, Bayes=6.5053,
Shibata $=6.3724$, Hannan-Quinn $=6.4282$ compare to other models of $\mathrm{c}(1,1), \ldots, \mathrm{c}(3,3)$. It was noted that the higher the combination of numbers for fitting a GARCH model the higher the log-likelihood, Akaike, Bayes, Shibata, Hannan-Quinn. Having inferred that GARCH $(2,1)$ was the optimal, the optimal order of c $(2,1)$ was used to construct 
gjrGARCH $(2,1)$, apARCH $(2,1)$, iGARCH $(2,1)$, and csGARCH $(2,1)$ and it was deduced that the GARCH $(2,1)$ outperformed other variants for the distribution of crude oil prices. The economy recession Nigeria experienced around second quarter of 2015 would be due to the less profitability of oil price exchange via the benchmarks in the second regime and some falling prices or non-performing of these benchmarks of oil prices as well as the demand in of the crude products. From the optimal GARCH $(2,1)$ coefficients for crude oil for price for the fifteen years studied, the $\mathrm{p}$-values for AR (1), AR (2), MA (1), omega, alpha2, beta1 with 0.000000 , $0.000000, \quad 0.000000,0.006139,0.003106,0.005609$,
$0.000000<0.05$ are significantly cognate to the contribution of the $\operatorname{GARCH}(2,1)$ model. The sign bias test is meant to test the null hypothesis that the positive and negative shocks have same impact on the volatility. However, since the sign bias with coefficient 1.0337 , and P-value $=0.3028>0.05$, it implies that positive and negative shocks did not have the same impact on the volatility of crude oil prices. In a similar vein, since the P-values for negative and positive sign bias are $\mathrm{P}$-value $=0.7270>0.05$ and $\mathrm{P}$-value $=0.8287>0.05$ respectively, it implies both negative and positive shocks as no real meaningful impact on the volatility of crude oil prices.

\subsection{Model Selection for GARCH Variants' Models for Barrels of Crude Oil Produced}

Table 9. Model Selection for GARCH Model for the Barrels of Crude Oil Produced.

\begin{tabular}{|c|c|c|c|c|c|}
\hline GARCH Order & Log-likelihood & Akaike & Bayes & Shibata & Hannan-Quinn \\
\hline c $(1,1)$ & 130.5482 & -1.4739 & -1.3628 & -1.4764 & -1.4288 \\
\hline c $(2,1)$ & 130.5493 & -1.4621 & -1.3325 & -1.4654 & -1.4095 \\
\hline c $(2,2)$ & 130.5492 & -1.4503 & -1.3021 & -1.4545 & -1.3902 \\
\hline c $(3,1)$ & 130.5504 & -1.4500 & -1.3031 & -1.4520 & -1.374 \\
\hline c $(3,2)$ & 130.5503 & -1.4385 & -1.2718 & -1.4438 & -1.3708 \\
\hline c $(3,3)$ & 130.5525 & -1.4267 & -1.2415 & -1.4332 & -1.3515 \\
\hline
\end{tabular}

Table 10. Summary of GARCH Variants for the Barrels of Crude Oil Produced.

\begin{tabular}{lllll}
\hline GARCH variants & Log-likelihood & Akaike & Bayes & Shibata \\
\hline eGARCH $(1,1)$ & 131.2366 & -1.4703 & -1.3406 & -1.4735 \\
gjrGARCH $(1,1)$ & 132.5155 & -1.4854 & -1.3557 & -1.4886 \\
apARCH $(1,1)$ & 132.5518 & -1.4740 & -1.3258 & -1.4782 \\
iGARCH $(1,1)$ & 130.5292 & -1.4856 & -1.3930 & -1.4872 \\
csGARCH $(1,1)$ & 131.8664 & -1.4659 & -1.3177 & -1.4328 \\
\hline
\end{tabular}

Table 11. The Optimal iGARCH c $(1,1)$ Coefficients for the Barrels of Crude Oil Produced.

\begin{tabular}{|c|c|c|c|c|}
\hline Coefficients & Estimate & Std. Error & t-value & $\operatorname{Pr}(>|t|)$ \\
\hline $\mathrm{mu}$ & 2.486123 & 0.115723 & 21.483405 & 0.000000 \\
\hline ar1 & 0.988701 & 0.015838 & 62.427195 & 0.000000 \\
\hline mal & -0.3891 & 0.085718 & -4.539180 & 0.000006 \\
\hline omega & 0.00002 & 0.000015 & 0.030989 & 0.975279 \\
\hline alpha1 & 0.000002 & 0.015450 & 0.000098 & 0.99992 \\
\hline beta1 & 0.99998 & 0.286590 & 0.089254 & 0.000000 \\
\hline
\end{tabular}

Sign Bias Test

\begin{tabular}{lll}
\hline Coefficients & t-value & prob sig \\
\hline Sign Bias & 0.2027 & 0.0002 \\
Negative Sign Bias & 0.39407 & 0.6940 \\
Positive Sign Bias & 0.04913 & 0.0000 \\
Joint Effect & 0.50974 & 0.9167 \\
\hline
\end{tabular}

$$
\sigma_{t}^{2}=0.00002+0.9887 y_{t-1}-0.3891 \varepsilon_{t-1}+0.000002 \alpha_{1}+0.99998 \beta_{1}
$$

\subsection{Model Selection for GARCH Variants'Models for Barrels of Crude Oil Exported}

Table 12. Model Selection for GARCH Model for Barrels of Crude Oil Exported.

\begin{tabular}{lllll}
\hline GARCH Order & Log-likelihood & Akaike & Bayes & Shibata \\
\hline c $(1,1)$ & 130.5482 & -1.4739 & -1.3628 & -1.4764 \\
c $(2,1)$ & 130.5493 & -1.4621 & -1.3325 & -1.4654 \\
c $(2,2)$ & 130.5492 & -1.4503 & -1.3021 & -1.4545 \\
c $(3,1)$ & 132.3985 & -1.4722 & -1.3240 & -1.4764 \\
c $(3,2)$ & 130.5503 & -1.4385 & -1.2718 & -1.4438 \\
c $(3,3)$ & 130.5525 & -1.4267 & -1.2415 & -1.4332 \\
\hline
\end{tabular}


Table 13. Summary of GARCH Variants for the Barrels of Crude Oil Exported.

\begin{tabular}{llllll}
\hline GARCH variants & Log-likelihood & Akaike & Bayes & Shibata & Hannan-Quinn \\
\hline eGARCH $(1,1)$ & 131.2369 & -1.4703 & -1.3406 & -1.4735 & -1.4176 \\
gjrGARCH $(1,1)$ & 132.5155 & -1.4854 & -1.3557 & -1.4886 & -1.4328 \\
apARCH $(1,1)$ & 132.5518 & -1.4740 & -1.3258 & -1.4782 & -1.4139 \\
iGARCH $(1,1)$ & 130.5292 & -1.4856 & -1.3930 & -1.4872 & -1.4480 \\
csGARCH $(1,1)$ & 131.8664 & -1.4659 & -1.3177 & -1.4701 & -1.4057 \\
\hline
\end{tabular}

From table 9 to table 13; from the model selection of GARCH models for barrels of crude oil produced and exported, it was glaring that the optimal integrated order after first differencing for barrels of crude oil produced and exported series coincide at $\mathrm{c}(1,1)$ ( that is optimal at AR (1) and MA (1) with coincide minima indexes of log-likelihood $=130.5482$, Akaike $=-1.4739$, Bayes $=-1.3628$, Shibata $=-1.4764$, Hannan-Quinn $=-1.4288$ compare to other models of $\mathrm{c}(2,1), \ldots, \mathrm{c}(3,3)$. It was noted that the higher the combination of numbers for fitting a GARCH model the higher the log-likelihood, Akaike, Bayes, Shibata, Hannan-Quinn as experienced. Having deduced that GARCH $(1,1)$ was the optimal, the optimal order of $\mathrm{c}(1,1)$ was used to construct eGARCH $(1,1)$, gjrGARCH $(1,1)$, apARCH $(1,1)$, $\operatorname{iGARCH}(1,1)$, and csGARCH $(1,1)$ and it was deduced that iGARCH $(1,1)$ outperformed GARCH $(1,1)$ and it other variants for the distribution of both barrels of crude oil produced and exported. From the optimal GARCH $(1,1)$ coefficients for barrels of crude oil produced and exported for the fifteen years studied, the P-values for AR (1), MA (1), betal with $0.000000,0.000006,0.000000$, and $0.000000<0.05$ are significantly important covariates to the contribution of the iGARCH $(1,1)$ model, while omega and alpha with P-values 0.975279 and $0.99992>0.05$ are insignificant to the $\mathrm{iGARCH}$ $(1,1)$. However, since the sign bias with coefficient 0.2027 , and $\mathrm{P}$-value $=0.0002<0.05$, it implies that positive and negative shocks have same impact on the volatility of barrels of crude oil produced and exported. In other words, since the P-values for negative and positive sign bias are $0.6940>0.05$ (with coefficient 0.39407 ) and $0.0000<0.05$ (with coefficient 0.04913) respectively, it implies positive shock as real meaningful impact on the volatility on barrels of crude oil produced and exported while negative shock as no real meaningful impact on the volatility on barrels of crude oil produced and exported.

\section{Conclusion}

In conclusion, there are instances where both or either the two sided (positive and negative shocks) that accompanied volatility cannot be ascertained for returns like crude oil distributions. In cases, the leverage effect fails to be modeled by $\mathrm{GARCH}$, it variants via the addition of positive and negative shocks on the conditional variance asymmetrically, asymmetric power, fractionally integrated to GARCH can be considered so as to model series like crude oil distribution series that contaminated leptokurtosis that is present in high-frequency and long memory. The positive and negative shocks have no same impact on the volatility of crude oil prices that optimal model for $\operatorname{GARCH}(2,1)$ out of its variants. The positive shock as real meaningful impact on the volatility on barrels of crude oil produced and exported while negative shock as no real meaningful impact on the volatility on barrels of crude oil produced and exported. In ratiocination, there are instances that the GARCH model would not be able to ascertain the type of shocks (positive or negative) associated to a series, in such scenario, the need for its variants will be over-emphasized.

\section{References}

[1] Ayere, T. O. (2020). Crude oil price fluctuation and inflation in Nigeria. Advances in Social Sciences Research Journal, 4 (3). doi: 10.14738/assrj.432757.

[2] Beine, M., Laurent, S., \& Lecourt, C. (2002) Accounting for conditional leptokurtosis and closing days' effects in FIGARCH models of daily exchange rates. Applied Financial Economics, 12: 589-601.

[3] Bollerslev T. (1986). Generalized Autoregressive Conditional Heteroscedasticity. Journal of Econometrics, 31, 307-327.

[4] Box, G. E. P., \& Jenkins, G. M. (1970). Time Series Analysis, Forecasting and Control. Holden Day, San Francisco.

[5] Chioma, N. N. \& Oyedele, A. A. (2017). Simulation and Hedging Oil Price with Geometric Brownian Motion and Single-Step Binomial Price Model. European Journal of Business and Management, 9 (9), 68-81, ISSN 2222-1905.

[6] Cifter, A. (2012). Volatility Forecasting with Asymmetric Normal Mixture GARCH Model: Evidence from South Africa. Romanian Journal of Economic Forecasting, 2, 127-142.

[7] Christoffersen, P. (1998). Evaluating interval forecasts. International Economic Review, 39, 841-862.

[8] Ding, Z., Granger, C. \& Engle, R. (1993). A long memory property of stock returns and a new model. Journal of Empirical Finance, 1, 83-106.

[9] Enders, W. (2004). Applied Econometric Time Series, $2^{\text {nd }}$ Edition. In: Wiley Series in Probability and Statistics. John Wiley \& Sons, Inc., Hoboken.

[10] Engle, R. F. (1982). Autoregressive Conditional Heteroskedasticity with Estimates of the Variance of United Kingdom Inflation. Economtrica, 50 (4), 987-1008.

[11] Erygit, M. (2012). The dynamical relationship between oil price shocks and selected macroeconomic variables in Turkey. Economic Research, 25 (2), 263-276. Doi: 10.1080/1331677X.2912.11517507.

[12] Falade A. (2016). Econometrics Analysis of Oil Prices on Nigerian Financial Economic. JORIND, (9) 1. ISSN 1596-8303. www.transcampus.org/journals. 
[13] Fryzlewicz, P. (2007). Lecture notes: Financial time series, ARCH and GARCH models, Department of Mathematics, University of Bristol, Bristol BS8 1TW, UK, p.z.fryzlewicz@bristol.ac.uk.

http://www.maths.bris.ac.uk/ mapzf/.

[14] Glosten, L., Jagannathan, R. \& Runkle, D. (1993). On the relation between expected return on stocks, Journal of Finance, 48: 1779-801.

[15] Hassan, S. A. \& Regassa, H. (2016). Asymmetric behavior of volatility in gasoline prices across different regions of the United States. Journal of Finance and Accountancy, 1-9.

[16] Lambert, P. \& Laurent, S. (2001). Modelling financial time series using GARCH-type models and a skewed student density, mimeo, Universite' de Lie'ge.

[17] Lambert, P. \& Laurent, S. (2000). Modelling skewness dynamics in series of financial data, Discussion Paper, Institut de Statistique, Louvain-la-Neuve.

[18] Lim, C. M. \& Sek, S. K. (2013). Comparing the performances of GARCH-type models in capturing the stock market volatility in Malaysia. Procedia Economics and Finance, 5, 478-487.

[19] Liu, S. \& Brorsen, B. (1995) Maximum likelihood estimation of a GARCH-stable model. Journal of Applied Econometrics, $10,273-85$.

[20] Mandelbrot, B. (1963). The variation of certain speculative prices, Journal of Business, 36, 394-419.
[21] Maqsood, A., Safdar, S., Shafi, R., Lelit, N. J. (2017). Modeling Stock Market Volatility Using GARCH Models: A case study of Nairobi Securities Exchange (NSE). Open $\begin{array}{llll}\text { Journal of } & \text { Statistics, } 7 & \text { (2), 369-381. }\end{array}$ https://doi.org/10.4236/ojs.2017.72026.

[22] Naimy, V. Y. (2013) Parameterization of GARCH $(1,1)$ for Stock Market. American Journal of Mathematics and Statistics, $3,357-361$

[23] Nelson, D. B. (1991). Conditional Heteroskedasticity in asset returns: A new approach. Econometrica, 59 (2), 347-370. https://doi.org/10.2307/2938260.

[24] Oriakhi, D. E., \& Osaze, I. D. (2013). Oil Price volatility and its consequences on the growth of the Nigerian economy: An examination (1970-2010). Asian Economic and Financial Review, 3 (5), 683-702.

[25] Peter, E. A. (2011). The Impact of Oil Price on the Nigerian Economy. Journal of Research in National Development, 9 (1).

[26] Posedel, P. (2005). Properties and Estimation of GARCH $(1,1)$ Model. Metodolskizvezki, 2, 243-257.

[27] Taylor, S. (1986). Modelling financial time series. New York: Wiley and Sons.

[28] Xekalaki, E. \& Degiannakis, S. (2010). ARCH models for financial applications. John Wiley \& Sons Ltd.

[29] White, H. (2000). Reality check for data snooping. Econometrica, 68, 1097-1126. 